\title{
Numerical Simulation of the Combustion Stability for Low Concentration Methane in a Perfectly-stirred Reactor
}

\author{
Quan-Wei DENG ${ }^{1,2, a}$, Xin-Hua LIU ${ }^{3, b}$, Qi-Zhao LINc,, \\ ${ }^{1}$ Department of Thermal Science and Energy Engineering, USTC, Hefei 230000, China \\ ${ }^{2}$ School of Safety Science and Engineering, Henan Polytechnic University, Jiaozuo 454150, China \\ ${ }^{3}$ Department of Safety and environmental protection, Henan Billions Chemicals Co., Ltd, Jiaozuo \\ 454191, China \\ aqwdeng@mail.ustc.edu.cn, bannie0811@126.com, qlin@ustc.edu.cn
}

${ }^{*}$ Corresponding author

Keywords: Combustion Stability, Low Concentration Methane, Perfectly-stirred Reactor.

\begin{abstract}
The combustion stability of low concentration methane in a perfectly-stirred reactor is numerically studied by Chemkin software and GRI-Mech 3.0 mechanisms, considering the influence factors of residence time, methane concentration, preheating temperature and heat loss, the following conclusions can be drawn: (1) To maintain low concentration methane combustion stability, it is need to make the residence time in the reactor larger than the critical residence time or the mass flow rate less than the critical mass flow rate. (2) To make the methane concentration below $4 \%$ combustion stability, it should be preheated to improve chemical reaction speed, methane concentration decreased by $1 \%$, corresponding to increasing preheating temperature of about $200 \mathrm{~K}$. (3) Heat loss can significantly reduce the initial temperature, and thus lead to reduce the critical mass flow. The key factor of control the heat loss is reinforces insulation measures or reduces the heat transfer coefficient.
\end{abstract}

\section{Introduction}

Low concentration methane combustion belongs to the typical lean combustion, due to low calorific value, more inert gas and long ignition delay time, the combustion process prone to unstable combustion, incomplete combustion, even to extinction phenomenon. Therefore, the combustion stability of low concentration methane is one of the core problems of the realization of low concentration methane.

Combustion stability refers to maintain a certain position and volume in the specific combustion conditions, neither to flashback, nor to extinguish. The combustion stability of methane/air is one of the characteristics of methane combustion, attracted many scholars to study it. Jones[1] and Paul D. Ronney[2] based on heat balance model studied the zero dimensional extinguishing process and one-dimensional combustion stability respectively. Kalghatgi[3,4] studied the liftoff flame characteristics of hydrocarbon-air, and obtained the general blowout curve of methane, propane, ethylene fuel. TIAN Ying[5] studied the flashback characteristics of lean premixed combustion and draw the conclusion that ring shape holder shows the best while swirl holder the worst on anti-flashback performance. JIANG Yong[6] studied the behaviors of hydrogen-enriched premixed methane/air flames and the results showed that extinction strain rate and lean flammability limit were significantly extended due to the presence of hydrogen in the mixture. ZHONG Beijing[7] studied the extinction limits of micro-scale catalytic combustion and the results showed that the micro-channel conducting wall significantly affects the flame stability. Li Yan-xia[8] studied the combustion and heat transfer characteristics in the micro combustors and the results showed that the increasing of transverse fins in a small tube could prevent the blow out phenomenon occurring.

For the combustion stability of methane, most of the literatures are focused on high concentration methane, while for the low concentration methane, critical mass flow rate will be significantly reduced, which is more prone to cause extinction phenomenon. Take the ventilation air methane as 
the background, the paper numerically studies the influence factors of affecting the combustion stability of low concentration methane, and hope to provide theoretical and technical support for a certain effective utilization of low concentration methane.

\section{Model Formulations}

Perfectly stirred reactor (PSR) refers to the reactor in the control container through stirring to completely mixed, it is a kind of ideal state. Usually, as shown in Fig.1 below, using a high speed jet entrance to make the reaction fluid to fill the whole reactor vessel for a moment, the parameters of each point in the container is the same. PSR is often used in many researches on the combustion characteristics of the flame stability, the formation of $\mathrm{NO}_{\mathrm{X}}$, and the influencing parameters of global reaction.

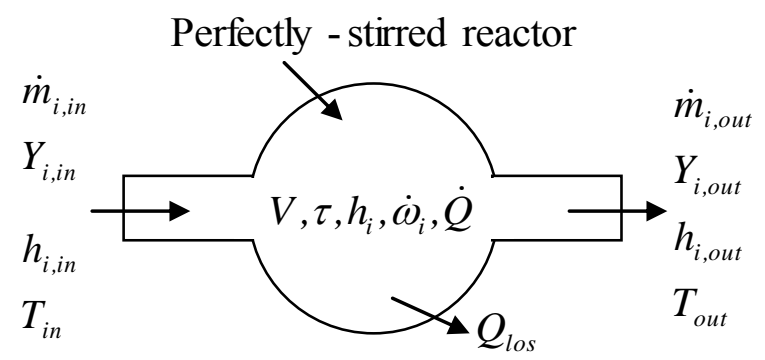

Fig.1 Schematic of a perfectly-stirred reactor

The governing equations written in conservative form are as follows:

Mass balance equation

$$
\frac{d m_{i}}{d t}=\dot{m}_{i}^{\prime \prime \prime} V+\dot{m}_{i, \text { in }}-\dot{m}_{i, \text { out }}
$$

Species equation

$$
\dot{\omega}_{i} M W_{i} V+\dot{m}\left(Y_{i, \text { in }}-Y_{i, \text { out }}\right)=0
$$

Energy equation

$$
\dot{Q}=\dot{m}\left(\sum_{i=1}^{N} Y_{i, \text { out }} h_{i}(T)-\sum_{i=1}^{N} Y_{i, \text { in }} h_{i}\left(T_{\text {in }}\right)\right)
$$

State

$$
\rho=P W_{m i x} / R_{u} T
$$

Where, mass production rate of each species is $\dot{m}_{i}^{m}=\dot{\omega}_{i} W_{i}$, mass flow rate of each species is $\dot{m}_{i}=\dot{m} Y_{i}$, enthalpy is $h_{i}(T)=h_{f, i}^{0}+\int_{T_{r e f}}^{T} c_{p, i} d T$.

the residence time in the reactor is defined as:

$$
t_{R}=\rho V / \dot{m}
$$

Combined by the combustion mechanism of GRI-Mech 3.0, the above equations are solved by CHEMKIN software. The main purpose is to study the blowout characteristics of low concentration methane, and the influencing factors include the effect of residence time, methane concentration, preheat temperature and heat loss.

\section{Results and Discussions}

\section{Effects of Residence Time}

In order to study the effect of residence time on the combustion stability of low concentration methane, assuming the methane concentration is $5 \%$, the initial temperature is $298.15 \mathrm{~K}$, the reaction 
container is spherical vessel diameter $80 \mathrm{~mm}$, and the initial ignition temperature of the perfectly-stirred reactor is $1500 \mathrm{~K}$. When the residence time is large, the reactor will reach an equilibrium state, the initial setting dwell time is $1 \mathrm{~s}$, and then gradually decreased to $0.0001 \mathrm{~s}$.

Fig. 2 illustrates the effects of residence time on the reactor temperature, concentration of reactant and main resultant, respectively. It is easy to see from Fig.2 (a) that the reactor temperature gradually decreases with the reduction of residence time, when the residence time is less than $0.002 \mathrm{~s}$, the temperature suddenly dropped to the initial temperature of $298.15 \mathrm{~K}$, indicating that the combustion has been blown out. From Fig.2 (b) can see that the reactant concentration increases slowly with the decrease of residence time, when the residence time is less than $0.002 \mathrm{~s}$, the reactants are suddenly returns to the initial concentration. From Fig.2 (c) also see that residence time gradually decreases to $0.002 \mathrm{~s}$, the concentration of $\mathrm{H}_{2} \mathrm{O}$ and $\mathrm{CO}_{2}$ from a slow decrease to jump down to zero, and the concentration of $\mathrm{CO}$ is at first increased due to incomplete combustion and then decreased till to zero which shows that flame is extinguished, at this time, the residence time is the critical residence time for the flame blow out.

From the definition of the residence time, it can be obtained residence time and mass flow rate is inversely proportional, the critical residence time actually corresponds to the maximum mass flow rate, i.e. when the mass flow rate continue to increase, the flame will be blown out.

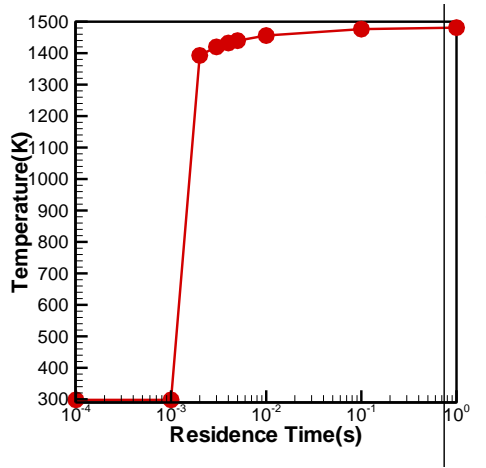

(a)temperature

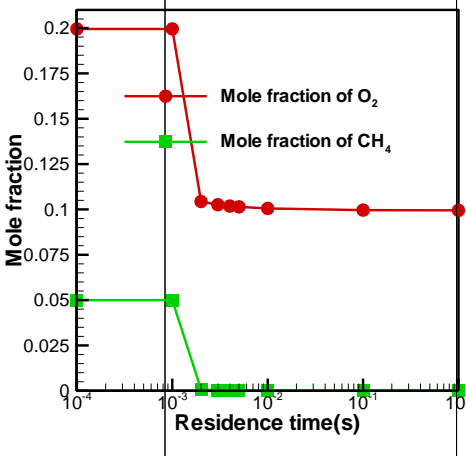

(b)reactant concentration

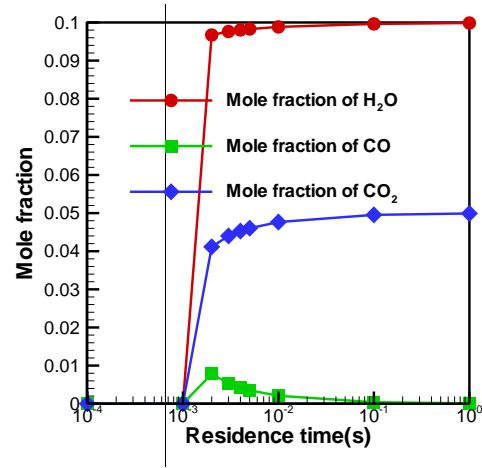

(c)main resultant concentration

Fig.2 Effects of Residence Time on the Reactor Temperature, Reactant and Main Resultant Concentration for $5 \%$ Methane Concentration

\section{Effects of Methane Concentration}

In order to investigate the effect of methane concentration on the stability of combustion, assuming the reactor is adiabatic, the initial temperature is $298.15 \mathrm{~K}$, the reaction container is spherical vessel diameter $80 \mathrm{~mm}$, and the initial ignition temperature of the perfectly-stirred reactor is $1500 \mathrm{~K}$. The methane concentration at first assumed to be $5 \%$, and then gradually reduce the methane concentration, study the critical mass flow rate under different methane concentrations.

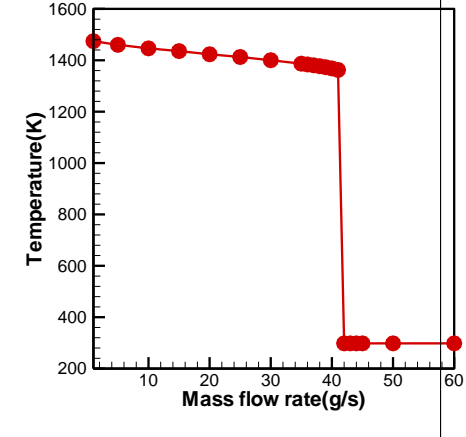

(a)temperatur

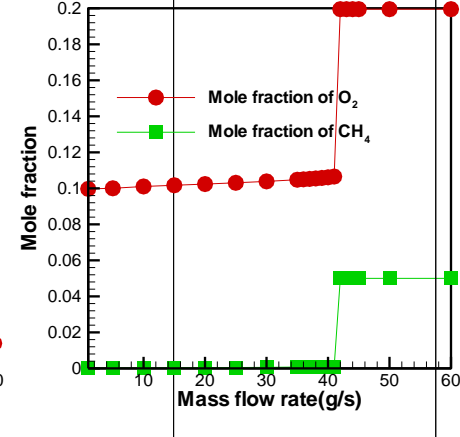

(b)reactant concentration

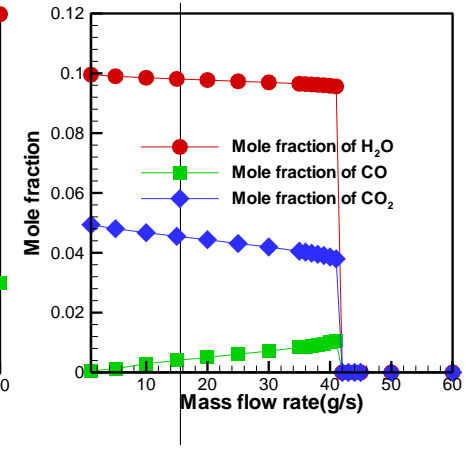

(c)main resultant concentration

Fig.3 Effect of Mass Flow Rate on Combustion Stability for 5\% Concentration Methane

Fig. 3 indicates the variation of the reactor temperature, concentration of reactant and main resultant with the mass flow rate of 5\% concentration methane. As can be seen from Fig.3 (a), along 
with the increase of mass flow, the temperature gradually decreased, when the mass flow rate is $41 \mathrm{~g} / \mathrm{s}$, the temperature suddenly dropped to the initial temperature of $298.15 \mathrm{~K}$, which show that the combustion is blown out. From Fig.3 (b) can be seen that the concentration of reactant increase slowly with increased mass flow, when the mass flux is larger than $41 \mathrm{~g} / \mathrm{s}$, the reactants are suddenly returns to the initial concentration. It can be also seen from Fig.3 (c), mass flow rate is greater than $41 \mathrm{~g} / \mathrm{s}$, the concentration of resultant are suddenly drop to zero, indicating that the flame has been blow out, i.e. $41 \mathrm{~g} / \mathrm{s}$ is the critical mass flow rate at this condition.

Fig.4 illustrates the variation of the reactor temperature, concentration of reactant and main resultant with the mass flow rate of $1 \%$ concentration methane. Reduces the mass flow to the $0.01 \mathrm{~g} / \mathrm{s}$, it is still not burn. Fig.5 shows the critical mass flow rate without preheating under different methane concentration, it is easy to get from the Figure, along with the reducing methane concentration, the critical mass flow rate of stable burning decreased gradually with decreasing methane concentration, the mass flow rate of $4 \%$ methane concentration is $2 \mathrm{~g} / \mathrm{s}$, and the mass flow rate is $0.02 \mathrm{~g} / \mathrm{s}$ at $3 \%$ methane concentration. Furthermore, the critical mass flow rate of stable burning at the actual burner will be less than this value, which means that in this concentration, without preheating, stable combustion cannot be achieved.

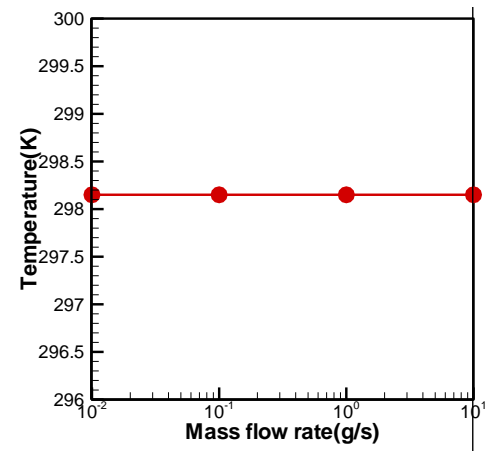

(a)temperature

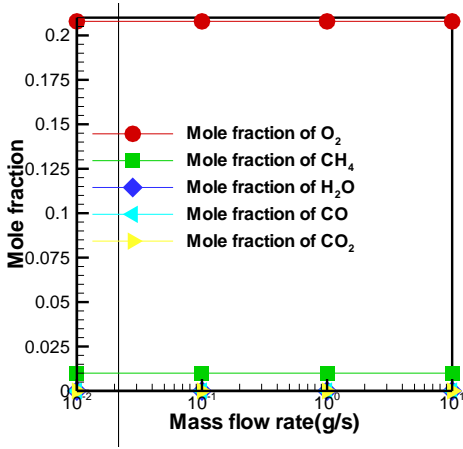

(b) concentration of reactant and main resultant

Fig.4 Effect of Mass Flow Rate on Combustion Stability for 1\% Concentration Methane

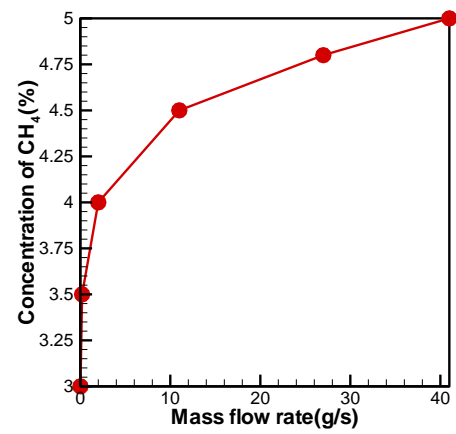

Fig.5 The Critical Mass Flow Rate of Different Methane Concentration without Preheating

\section{Effects of Preheating Temperature}

By the above analysis of methane concentration to combustion stability, lower than $4 \%$ concentration, but to realize the stable combustion, need to take the preheating method. In order to study the influence of preheating temperature of methane combustion stability, reaction vessel is still assumed to be spherical vessel diameter $80 \mathrm{~mm}$, and the initial ignition temperature is $1500 \mathrm{~K}$.

Fig.6 (a) shows the effect of preheating temperature on combustion stability for $3 \%$ methane concentration, easy to get from the figure, with the increase of preheat temperature, the critical mass flow rate of stable combustion increases gradually, when the preheating temperature is $400 \mathrm{~K}$, the critical mass flow rate is $0.2 \mathrm{~g} / \mathrm{s}$, when the preheating temperature increases to $800 \mathrm{~K}$, the critical mass flow reaches $88 \mathrm{~g} / \mathrm{s}$. If you want to make the critical mass flow rate higher than $1 \mathrm{~g} / \mathrm{s}$, it will need at least a preheating temperature of 500K. Fig.6 (b) shows the effect of preheating temperature on combustion stability for $2 \%$ methane concentration, similarly, the critical mass flow rate 
increases with the increasing preheating temperature. To make the critical mass flow rate higher than $1 \mathrm{~g} / \mathrm{s}$, it will need at least a preheating temperature of 700K. From Fig.6 (c), it will be obtained, if you want to make the critical mass flow rate higher than $1 \mathrm{~g} / \mathrm{s}$ at $1 \%$ methane concentration, it will need at least a preheating temperature of $900 \mathrm{~K}$. Namely the methane concentration decreased $1 \%$, corresponding to increasing preheating temperature of about $200 \mathrm{~K}$.

The methane concentration is higher than $1 \%$, the mutation point of temperature and the point of maximum $\mathrm{CO}$ concentration are the same as Fig.2 and Fig. 3 show, but when methane concentration is less than 1\%, it is different as Fig.6 (d) shows. In fact, at this concentration, it becomes a process of slow oxidation. Fig.6 (d) shows the effect of preheating temperature on combustion stability for $0.5 \%$ methane concentration, when $\mathrm{CO}$ concentration achieves maximum value, the temperature is no longer a mutation occurs, but with the increase of mass flow rate gradually decreased, while the concentration of $\mathrm{CO}$ is still at first increases and then decreases, when the $\mathrm{CO}$ concentration reached the maximum value, take the flow rate of this point as critical mass flow rate. It is mainly due to the increase of preheating temperature, flame hard to extinguish, but the oxidation degree decreased gradually, while the concentration of $\mathrm{CO}$ reached the maximum value, although the temperature does not reach the initial preheating temperature, but methane has been unable to maintain stable oxidation.

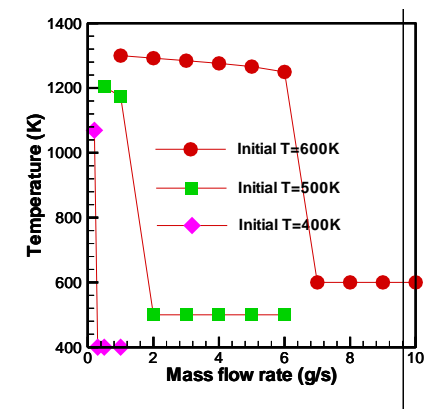

(a) $3.0 \%$ methane concentration

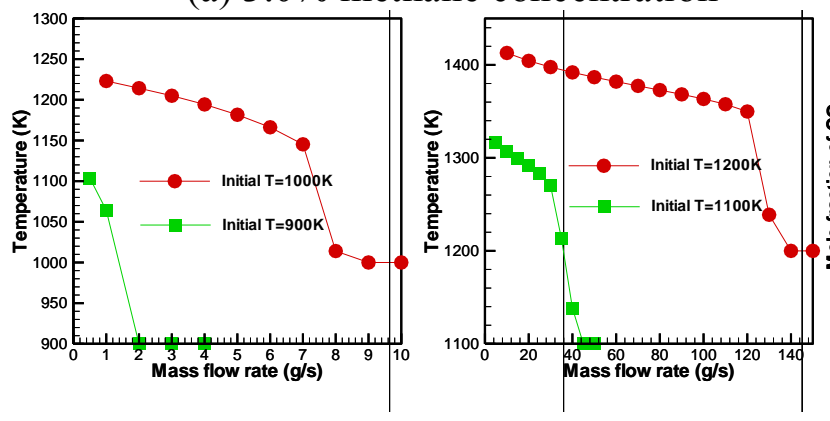

(c) $1.0 \%$ methane concentration
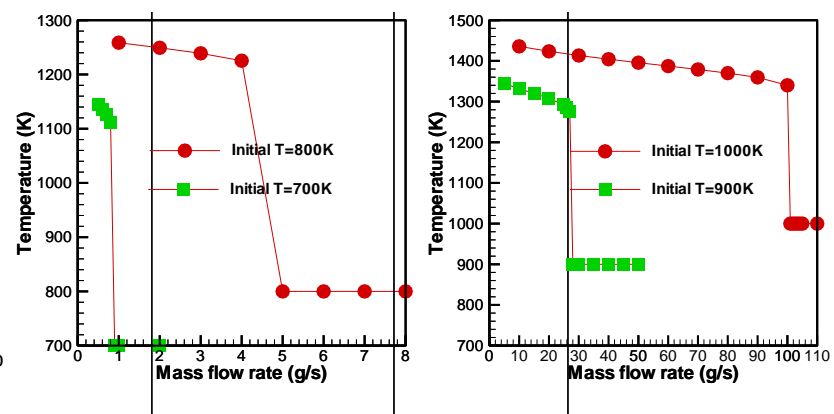

(b) $2.0 \%$ methane concentration
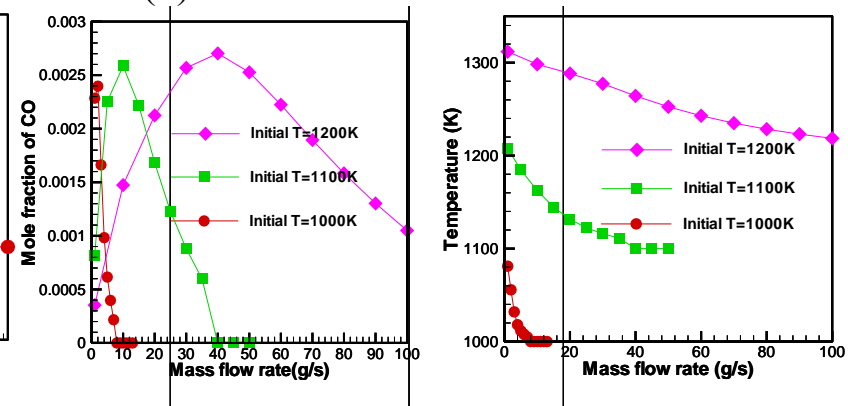

(d) $0.5 \%$ methane concentration

Fig.6 Effect of Preheating Temperature on Combustion Stability for Low Concentration Methane

\section{Effects of Heat Loss}

From the above effect of preheating temperature on combustion stability, high preheating temperature is a necessary condition for low concentration methane oxidation. In order to study the effects of thermal losses on low concentration methane burning, assuming the reaction vessel for spherical vessel diameter $80 \mathrm{~mm}$, the initial ignition temperature is $1500 \mathrm{~K}$, and the methane concentration is $1 \%$ with preheating temperature of $1000 \mathrm{~K}$.

Fig.7 (a) shows the effect of total heat loss on combustion stability for $1 \%$ concentration methane, easy to get from the figure, along with the enhancement of the heat loss, on the one hand, there is a tendency of reducing the critical mass flow rate; on the other hand, the total temperature reduces with the increasing of the total heat loss, when the initial flow rate is $1 \mathrm{~g} / \mathrm{s}$, the reduction of temperature is most obvious, comparing heat loss of $27 \mathrm{cal} / \mathrm{s}$ and adiabatic, the temperature different is about $160 \mathrm{~K}$. When heat loss is more than $27 \mathrm{cal} / \mathrm{s}$, the initial temperature is very close to the 
preheating temperature, and cause the error calculation, heat loss at this time can be deemed to the critical heat loss to maintain stable combustion.

From the heat transfer to consider it, taking heat from a certain sense is actually a heat loss. According to Newton's law of cooling, heat and heat transfer coefficient is proportional. Assume that the mass flow rate is $5 \mathrm{~g} / \mathrm{s}$, the spherical heat exchange area is $201 \mathrm{~cm} 2$, preheating temperature is $1000 \mathrm{~K}$, the environmental temperature is $298.15 \mathrm{~K}$. Fig.7 (b) shows the effects of heat transfer coefficient on the combustion temperature for $1 \%$ concentration methane, as can be seen from the graph, the temperature decreases with the increase of heat transfer coefficient. When the temperature of outlet flue gas is equal to the reactor temperature, while the temperature of $1000 \mathrm{~K}$ flue gas cannot preheat $1 \%$ concentration methane to $1000 \mathrm{~K}$, i.e. flue gas heat recycling cannot be sustaining self oxidation reaction. Therefore, there is a critical heat transfer coefficient of $0.00023 \mathrm{cal} / \mathrm{m}^{2} \cdot \mathrm{K}$. When the heat transfer coefficient is higher than this value, it can't maintain a stable combustion. It shows that for the combustion of low concentration methane, higher heat preservation material is necessary.

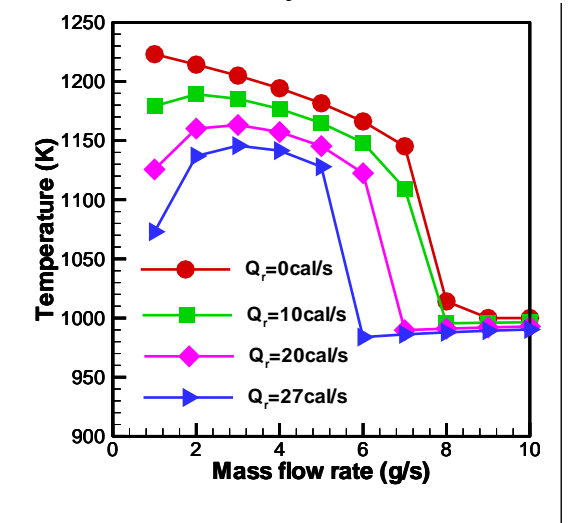

(a)heat loss

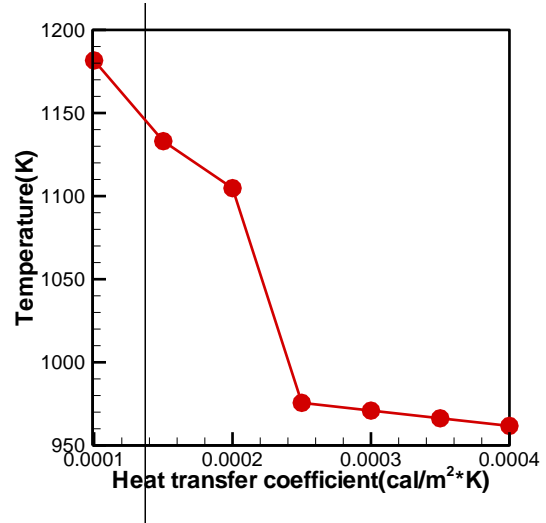

(b)heat transfer coefficient

Fig.7 Effect of Heat Loss (a) and heat transfer coefficient (b) on combustion stability for $1 \%$ concentration methane

\section{Conclusions}

The combustion stability of low concentration methane in a perfectly-stirred reactor is numerically studied by Chemkin software, and the main factors including residence time, methane concentration, preheating temperature and heat loss. The following main conclusions can be drawn:

(1) To maintain low concentration methane combustion stability, it is need to make the residence time in the reactor larger than the critical residence time or the mass flow rate less than the critical mass flow rate. Otherwise, the flame will be blown out.

(2) With the reducing methane concentration, the critical mass flow of stable burning decreases gradually. To make the methane concentration below 4\% combustion stability, it should be preheated to improve chemical reaction speed, methane concentration decreased by $1 \%$, corresponding to increasing preheating temperature of about $200 \mathrm{~K}$.

(3) Heat loss can significantly reduce the initial temperature, and thus lead to reduce the critical mass flow. The key factor of control the heat loss is reinforces insulation measures or reduces the heat transfer coefficient.

\section{Acknowledgement}

This research was financially supported by the National Science Foundation (51376171), the Natural Science Foundation of Henan Province Education Department (2011B440001), Youth Fund of Henan Polytechnic University (Q2009-4). 


\section{References}

[1]A.R.Jones, S.A.Lloyd and F.J.Weinberg. Combustion in heat exchanger [J]. Proc. R. Soc. Lond. A, 1978, 360:97-115.

[2]Paul D. Ronney. Analysis of non-adiabatic heat-recirculating combustors [J]. Combustion and Flame, 2003, 135: 421-439.

[3]Kalghatgi.G.T. lift-off heights and visible lengths of vertical turbulent jet diffusion flames in still air. Combustion science and technology. 1984,41:17-29

[4]Kalghatgi.G.T. Blow-out stability of gaseous jet diffusion flames. PartI: in still air. Combustion and technology. 1981, 26:233-239.

[5]TIAN Ying, XU Gang, SONG Quan-Bin etc. Flashback characteristics of lean premixed combustion. Journal of Engineering Thermophysics, 2006,27(5):871-874

[6]JIANG Yong, QIU Rong, SONG Chong-lin. Numerical predictions of hydrogen-enriched premixed methane/air flames. Journal of Combustion Science and Technology, 2009, 15(3):196-202.

[7]ZHONG Beijing,JIAO Jian. Extinction limits of CH4/air premixed combustion in a microchannel. Journal of Tsinghua University(Science and Technology), 2007,47(11):2044-2047.

[8]Li Yan-xia. Combustion and heat transfer characteristics in the Micro Combustors [D]. BeiJing: Beijing University of Technology, 2012. 